\title{
Palabras pronunciadas por el doctor Fernando Sánchez Torres durante la sesión solemne del día 19 de marzo de 1993, conmemorativa de los 50 años de fundación de la Sociedad Colombiana de Obstetricia y Ginecología
}

Diez días faltan para que se cumpla exactamente medio siglo de haberse fundado la Sociedad de Obstetricia de Colombia, transformada luego en Sociedad Colombiana de Obstetricia y Ginecología, organizadora de el acto que esta noche nos congrega. Su junta directiva ha querido que sea yo quien haga la rememoración de aquella efeméride, no obstante pervivir aún distinguidos colegas que fueron testigos de excepción de ese acontecimiento y que, de seguro, conservan todavía fresco su recuerdo. El que yo haya incursionado en el transcurrir histórico de nuestra especialidad, ha sido, sin duda, la razón de fondo que ha movido a los directivos de la Sociedad a escogerme como orador, encargo que he aceptado gustoso por cuanto me honra sobremanera. Por ello dejo testimonio de gratitud.

Colocándome en condición de historiador debo inevitablemente trasladarme a la época en que ocurrió el hecho que queremos recordar, para conocer las circunstancias que lo rodearon y poderle dar su justo valor. En ese entonces, 1943, todavía se escuchaba el fragor de la Segunda Guerra Mundial, que, por más de una década, había aislado del Viejo Continente a los países latinoamericanos. Por eso varias promociones de médicos se vieron privadas de poder viajar a los más importantes centros científicos allende el mar, en especial a los de Francia, como era costumbre en aquellas calendas. En efecto, el profesional de la medicina que quisiera superar el nivel común de sus colegas, debía permanecer algún tiempo en Europa al lado de los legendarios maestros, ojalá en la Ciudad Luz, que era, como afirmara la escritora española Emilia Pardo Bazán, el alambique donde se destilaba la quinta esencia del pensamiento moderno. Los más connotados profesores de la Facultad de Medicina de la Universidad Nacional, que era la única escuela que existía en Bogotá, respaldaban su currículo académico con títulos obtenidos en universidades europeas. Así Miguel Rueda Acosta y Nicolás Buendía en el campo obstétrico; Rafael Ucrós Durán en el ginecológico. Ellos fueron los que modelaron intelectualmente a quienes irían a ser sus sucesores en la docencia y en el ejercicio profesional y que, por las razones expuestas, no abrevaron directamente en las fuentes foráneas. Es necesario anotar que la ginecología en los inicios de la década de los años 40 no tenía todavía un perfil propio, definido, como que se confundía con la cirugía general, no obstante existir en el pénsum académico de la Facultad la respectiva cátedra, fundada por Ucrós Durán en 1903, asignatura que era opcional. Como anécdota curiosa, Arturo Aparicio Jaramillo, uno de los primeros ginecólogos colombianos de verdad, formado en Chile al lado del maestro Juan Wood, no cursó ginecología a su paso por la escuela de medicina. La obstetricia, en cambio, se encontraba consolidada como especialidad desde finales del siglo XIX. Los profesores José del Carmen Acosta Villaveces y Víctor Rodríguez
Aponte, que sucedieron a Buendía y a Rueda Acosta, llegaron a ser admirables obstetras de impecable formación francesa, sin viajar a Francia en calidad de estudiantes.

No debe extrañarnos, pues, que la institución de la cual conmemoramos sus primeros cincuenta años de vida, haya sido fundada por obstetras y su nombre primigenio fuera el de Sociedad de Obstetricia de Colombia.

Como insinué antes, para aquella época, por legado francés, existía divorcio entre la obstetricia y la ginecología. En las principales ciudades del país la primera estaba parcialmente a cargo de hábiles especialistas, ya que cualquier médico solía hacer las veces de partero, sin importar la disciplina a la cual entregaba con preferencia sus horas de ejercicio. Eran los tiempos en que algunos se anunciaban como "especialistas en niños y en adultos", o como "especialistas en pacientes de ambos sexos". De ahí que Beruti, gran tocólogo argentino, dijera sabiamente que si la obstetricia no era para el médico práctico su mayor ocupación, sí era, en cambio, su mayor preocupación. Efectivamente, en un momento dado cualquier médico podía verse enfrentado a tener que atender un nacimiento.

Pese a existir unos cuantos centros asistenciales a donde podían acudir las mujeres en trance de parto, el nacimiento a domicilio mantenía su inveterado predominio. Aún recuerdo bien dos escenas captadas en el seno familiar, relacionadas con esa costumbre: Una, la figura abatida, derrotada, del médico de confianza de la casa que pocos momentos antes había hecho las veces de partero de la esposa de mi hermano mayor, con tan mala fortuna que el esperado primogénito quiso nacer en presentación de pelvis y falleció al momento de intentarlo. Ese improvisado tocólogo fue después mi maestro de Medicina Interna. Otra, la figura risueña del obstetra lavando los fórceps, luego de una exitosa aplicación en la alcoba de una de mis primas, que acababa de ser madre por primera vez. Este médico iría a ser pocos años después uno de los firmantes del acta de fundación de la Sociedad Colombiana de Obstetricia. Para complacencia de todos, superando quebrantos de salud, nos acompaña esta noche.

Despuntando el decenio de los 40, la maternidad del Hospital San Juan de Dios, ubicado desd-^acía quince años en predios de los molinos de La Hortúac era el refugio de las parturientas de escasos recursos económicos, pues allí no se cobraba un solo centavo por la atención que se les prestaba, como sí ocurría en el Pabellón Eliseo Montaña del Hospital de San José, la Clínica de Marly o la Clínica Calvo, situada en la carrera 13 entre calles 23 y 24 . Esta institución fue la primera destinada exclusivamente a la atención obstétrica privada que se abrió en Bogotá. Allí ocurrió un hecho importante, sin duda precursor del que dio origen a la Sociedad Colombiana de Obstetricia y Ginecología: el 7 de febrero de 1940, por invitación del 
doctor Jorge E. Calvo, director fundador de la Clínica, se reunió un grupo selecto de médicos radicados en la ciudad capital, con el ánimo de crear la "Sociedad de Ginecología y Obstetricia de Bogotá". Ese grupo estaba compuesto por los profesores Jorge Cavelier, urólogo distinguido, a la sazón rector de la Facultad de Medicina; Roberto Franco, sobresaliente investigador en el campo de las enfermedades tropicales; José del Carmen Acosta Villaveces y Víctor Rodríguez Aponte, titulares de la cátedra de Clínica Obstétrica de la Universidad Nacional. Además asistieron los doctores Manuel José Medellín, Nicolás Torres Barreto, Tulio Forero Villaveces, Rafael Manotas, Eudoro Castillo Vega, José Miguel Ruiz, Yesid Trebert Orozco, Hernando Acosta, Carlos Trujillo Venegas, Carlos Sáenz, Tomás Devia, Jorge Echeverri, Luis María Ferro, Camilo Becerra Navia y Jorge A. Calvo.

Expuestos los motivos de la reunión, fue acogida por todos la idea del doctor Calvo, designándose presidente honorario de la incipiente Sociedad al profesor Franco, presidente activo al profesor Acosta Villaveces, vicepresidente al profesor Ucrós Durán y como secretario al doctor Jorge A. Calvo. La agremiación científica que nacía bajo tan buenos auspicios no alcanzó siquiera a legalizar su constitución, pues pronto surgió una división entre sus miembros, originada por el querer de algunos de ellos, liderados por Hernando Acosta, en el sentido de que sólo podrían pertenecer a la institución los profesionales vinculados a la Facultad de Medicina o a los hospitales que tuvieran servicio de maternidad. Como puede deducirse, lo que se pretendía era que la Sociedad estuviera compuesta exclusivamente por parteros de escuela, es decir, verdaderos tocólogos.

Creo yo que quienes así obraban, imponiendo un criterio excluyente o selectivo, lo que buscaban era cuestionar a aquellos que sin adecuada preparación hacían las veces de especialistas, $\boldsymbol{o}$, por lo menos, negarles la condición de tales, que de hecho la obtendrían si se les permitía ingresar a la Sociedad de Obstetricia. Esta actitud del doctor Hernando Acosta, que dio al traste con el buen propósito del doctor Calvo, sirvió para despertar conciencia entre los obstetras de verdad, respecto a la necesidad de asociarse para defender sus legítimos intereses y, simultáneamente, los intereses de las mujeres que iban a ser madres. Contrariando el querer de los tocólogos de arrogarse para sí la vigilancia de las embarazadas y la atención de sus partos, esas delicadas funciones, tanto en las zonas urbanas como rurales, continuaban siendo patrimonio de las comadronas, que ejercían su oficio a domicilio y sólo acudían al médico o a los hospitales cuando la situación había llegado a extremos desastrosos.

Algún escritor médico, cuyo nombre se me escapa, refiriéndose a ellas expresaba gráficamente que esperar a que reclamaran al tocólogo para un caso de parto difícil era como llamar a los bomberos cuando de la casa sólo quedaban los cimientos. En Bogotá, para subsanar en algo semejante peligro, el profesor Rafael Barberi fundó una escuela de parteras en el Hospital San Juan de Dios, la cual comenzó a dar sus frutos finalizando la década de los veinte. Recordando este singular hecho, el profesor Carlos Julio Mojica, en entrevista que le hice poco antes de su muerte, me describía a esas comadronas certificadas como "de tabaco, mantilla y telaraña”, para significar con ello lo anticuadas que seguían siendo.

Puede aceptarse, pues, que en el país se ejercía una obstetricia vulgar o popular, que era la que imperaba, y otra culta o elitista, que era la que desempeñaban los obstetras de escuela. La formación que éstos recibían, sin estar a la par con la más técnica de otras latitudes, podía considerarse como actualizada, con algo de desfase, es cierto. Pensemos que en lo que iba transcurrido del siglo XX, muy pocos progresos se habían alcanzado respecto a como había quedado la obstetricia al finalizar el siglo XIX. En mi concepto, tres fueron los grandes aportes hechos a esa disciplina en los primeros cuarenta años del actual centenio, verdaderos hitos históricos en su evolución. En primer lugar, el descubrimiento de la acción útero estimulante del extracto del lóbulo posterior de la hipófisis llevado a cabo por el inglés Henry Dale en 1906, sustancia comercializada con el nombre de pituitrina y puesta en uso entre nosotros por el profesor Miguel Rueda Acosta en 1910. Este hallazgo permitió más tarde aislar la fracción oxitócica casi pura-el famoso pitocín-, utilizada por primera vez con fines inductivos en infusión intravenosa contínua por el también inglés Page en 1942, entregando con ello al obstetra el instrumento que habría de convertirlo en el director del parto. Correspondió a los doctores Alejandro Kerguelen y Manuel José Gómez Palacino, aquél de la Universidad de Antioquia y éste de la Universidad Nacional, ensayar en Colombia el pitocin intravenoso para la inducción del parto. Ambos presentaron su experiencia en 1950 a manera de tesis de grado.

El cirujano alemán Adolph Kehrer, en septiembre de 1881 lleva a cabo una cesárea, en el mismo domicilio de la paciente, abriendo el útero con incisión transversa del segmento. No obstante el buen resultado obtenido, la técnica de Kehrer cayó en el olvido para ser revivida en 1907 por su compatriota Fritz Frank, de Colonia. Es este el segundo de los grandes progresos mencionados, como que la introducción de la técnica segmentaria transperitoneal le otorgó, de manera inobjetable y definitiva, mayor confiabilidad a la operación cesárea, a tal punto que en la Maternidad del Hospital San Juan de Dios -donde la había ejecutado, el primero, el doctor José del Carmen Acosta en 1920- su práctica alcanzó, en 1943, un índice de $1.99 \%$, causa de honda preocupación, ipor lo elevado!, según lo anotó en su tesis de grado Gonzalo Echeverry Parra, uno de los asistentes al acto de fundación de la Sociedad de Obstetricia, en condición de interno de la Maternidad.

La tercera gran aportación fue el empleo de la denominada "analgesia peridual contínua", lumbar o caudal, de la que habían hablado en 1901 Sicard y Cathelin en Francia, pero que los norteamericanos Hingson y Edwards dieron a conocer ampliamente en 1942. Entre nosotros, Antonio Martínez, de la Universidad de Antioquia, utilizó la infiltración lumbar como analgesia obstétrica en 1941; Francisco Hayder, de la Universidad de Cartagena, la caudal en 1943, año en que también comunicaron sus experiencias en Bogotá Jorge A. Calvo con la peridural contínua y Jorge Cristo con la caudal contínua. Este último, el doctor Cristo Saldivia, compañero de internado del doctor Echeverry Parra, fue asimismo testigo de la creación de la Sociedad. Creo no pasar de exagerado al afirmar que la analgesia o anestesia epidural se constituyó en una verdadera bendición, pues humanizó el parto, aliviando sus dolores y acortando su duración. Por eso la he incluido entre los grandes progresos alcanzados en el campo obstétrico, y que para la década de los 40 , que es el período en el cual tenemos centrada la atención, comenzaba a utilizarse tímidamente.

Un inquieto obstetra de la Escuela del Hospital San Juan de Dios, graduado de médico cuatro años antes en la Universidad Nacional y fungiendo como Jefe de la Clínica 
Obstétrica, convocó a sus colegas de especialidad a una reunión para el día 30 de marzo de 1943 en uno de los salones de la Maternidad. El motivo era promover la creación de una Sociedad de Obstetricia, con miras a elevar el nivel científico de dicha disciplina y a mejorar, a través de la agremiación, las condiciones de los que la practicaban. El personaje a quien me refiero era el doctor Rafael Peralta Cayón. Su invitación fue atendida con entusiasmo. A la cita acudieron el profesor Víctor Rodríguez Aponte que presidió la reunión- y los doctores Ricardo Forero Vélez, Joaquín Sarmiento, Eudoro Castillo Vega, Alfredo Pinto Valderrama, Enrique Hurtado Salazar, Juan José Salamanca, Eduardo Caballero Ferreira, Alvaro Combariza, Enrique Quiñones, Rafael Ramírez Merchán, Casimiro Daza, Santiago Lleras Codazzi y Hernando Caicedo Díaz. También se hicieron presentes los estudiantes que en el momento adelantaban su programa de internado en la Maternidad, y que más tarde irían a darle lustre a la especialidad. Por eso sus nombres deben ser recordados ahora, además de los de Gonzalo Echeverry Parra y Jorge Cristo Saldivia. Fueron ellos Eduardo Díaz, Ramón Francisco Sánchez, Jorge Escobar Soto, Juan Guzmán Blanco, Ernesto Guzmán y Luis María Medellín.

Informados los asistentes del propósito de la reunión, el doctor Peralta Cayón presentó a su consideración un proyecto de estatutos, entregado a una comisión ad hoc para su estudio. Se procedió luego a elegir la primera mesa directiva, la cual quedó conformada por el profesor José del Carmen Acosta como presidente, Rafael Peralta Cayón como vicepresidente y Ramón Francisco Sánchez como secretario.

La nueva Sociedad de Obstetricia comenzó a reunirse regularmente en el mismo sitio donde nació. El 27 de mayo tuvo lugar la primera sesión y durante ella el doctor Peralta dio lectura a su trabajo "Los fibromas endouterinos ante la clínica obstétrica y ante la obstetricia social". En la reunión del $1^{\circ}$ de julio el doctor Rafael Ramírez Merchán presentó un "Comentario a dos historias clínicas de embarazo ectópico". Al año siguiente, el 16 de septiembre de 1944, el Departamento de Justicia del Ministerio de Gobierno le concedió personería jurídica mediante resolución número 157.

Con el ánimo de difundir los trabajos dados a conocer en el seno de la Sociedad, su directiva promovió en mayo de 1945 la publicación de un boletín. Para darle cumplimiento a tal disposición fueron comisionados los doctores Hernando Acosta, Rafael Ramírez Merchán y Santiago Lleras Codazzi. Por motivos económicos dicho boletín solo vino a aparecer a fines de 1949. Como es bien sabido por todos ustedes, en 1950 el boletín fue reemplazado por la Revista Colombiana de Obstetricia y Ginecología, la cual se ha distinguido entre las de su género por su perseverancia y calidad. Sin duda, la fundación de una revista seria, de aparición continuada, constituye, junto con la realización periódica de congresos, la más positiva contribución de la Sociedad al progreso de la ginecobstetricia nacional.

Cuatro años después de fundada, la Sociedad Colombiana de Obstetricia sufrió un cambio de nombre y amplió su radio de acción. En efecto, en la sesión del 21 de mayo de 1947, los especialistas en ginecología, encabezados por el profesor Arturo Aparicio Jaramillo -de quien hice mención atrás- ingresaron a ella, llamándose a partir de entonces Sociedad Colombiana de Obstetricia y Ginecología. Por tal razón fue menester reformar los estatutos y solicitar nueva personería jurídica, la cual concedió el Ministerio de Justicia el 17 de octubre de 1949 con el número 253. Como vemos, en realidad fue en el año de 1947 cuando se constituyó la Sociedad, conformada por obstetras y ginecólogos. Empero, si nos guiamos por el hilo conductor de los acontecimientos, históricamente iremos a encontrar sus orígenes en la Sociedad de Obstetricia de Colombia nacida gracias a la intervención de Rafael Peralta Cayón.

Para darle vigencia al nombre de Sociedad Colombiana, fueron creándose poco a poco filiales suyas en diferentes ciudades del país, hasta cuando se creyó conveniente transformarla en una federación, como en efecto ocurrió en 1967 en la ciudad de Cúcuta, con ocasión del Séptimo Congreso Nacional de la especialidad. A raíz de ese acontecimiento, muchos intentos se han hecho para que su primigenio nombre desaparezca, por haber perdido la institución la competencia para ocuparse de los asuntos científicos y gremiales en el ámbito nacional. No es este el momento para terciar en la polémica. Lo evidente es que aún existe y sigue proyectándose más allá de los límites del área territorial en que se la quisiera ver confinada.

$\mathrm{Al}$ margen de lo que pueda ocurrir con su denominación en los días por venir, la Sociedad Colombiana de Obstetricia y Ginecología alcanzó a cumplir sus bodas de oro. Tal aniversario es lo que nos ha congregado esta noche, no sólo para festejarlo sino también para rendir un emocionado y justo homenaje a sus fundadores, presentes y desaparecidos. Para ellos pido un cálido aplauso. De igual manera, los invito a que batamos palmas de felicitación a la actual junta directiva de la Sociedad, presidida con sobrada diligencia por el doctor Jaime Ferro Camargo y María Teresa Peralta Abello, hija del gestor de la Sociedad, por no haber dejado pasar inadvertida tan señalada efeméride, y para agradecerle que nos hubiera brindado la feliz oportunidad de participar en los actos conmemorativos. 